\title{
Value-at-Risk Approach to Currency Crises: A Brazilian Example With the Central Bank and Currency Based Assets*
}

\author{
Marcelo Zeuli \\ Banco Central do Brasil, Rio de Janeiro, Brazil \\ IAG/PUC, Rio de Janeiro, Brazil
}

\begin{abstract}
This paper uses a Value at Risk (VaR) approach to evaluate a country financial vulnerability, by analyzing the risk exposure of its Central Bank, as if their assets are subject to market risk. The Brazilian currency exchange swaps contracts (US\$/Brazilian Reais) are submitted to a delta-normal VaR method, in order to evaluate the market risk of each swaps series, by modeling the variance of the daily returns, from August 1999 to January 2003. All daily returns series exhibited heteroscedasticity in the conditional variance and sudden changes in the unconditional variance. The points of changes of the unconditional variance were determined through the Iterative Cumulative Sum of Squares (ICSS) algorithm, and the conditional variance was modeled with Markov-Switching-Generalized Autoregressive Conditional Heteroscedasticity (SWGARCH) in order to capture heteroscedasticity and regime change. The results lead to two main conclusions: First, a VaR model must incorporate heteroscedasticity and regime switching in order to describe the variance of the tested series, submitted to brisk changes of economic and political scenarios. Second, a volatility-based VaR do not necessarily generate forward-looking indicators, but rather coincident indicators of possible financial vulnerabilities. The future research will evolve towards evaluating the effects of the Basel III recommendations as if they could be applied to this crisis period.
\end{abstract}

Keywords: emerging markets, market risk, volatility, GARCH models, regime switching

\section{Introduction}

This paper uses a Value at Risk (VaR) approach to evaluate the financial vulnerability of a country, analyzing the risk exposure of the assets of a Central Bank, as if they are subject to market risk. Dornbush (1998), apparently, was the first to suggest this approach, and Blejer and Schumacher (1998) detailed a VaR for Central Banks methodology and in complement to VaR, recommended stress tests based on the extreme value theory (EVT). According to Blejer and Schumacher (1998, p. 3), the 1990's currency crisis revitalized the search for antecedent indicators of financial vulnerability. The evaluation of solvency and vulnerability of a Central Bank—and, consequently, the vulnerability of a country—is relevant to the maintenance of its

\footnotetext{
* IAG/PUC and Banco Central do Brasil (Brazilian Central Bank). The views expressed in the paper are those of the author and do not necessarily reflect those of the Banco Central do Brasil.

Marcelo Zeuli, Analyst at Banco Central do Brasil; Ph.D. Candidate at IAG, PUC/RJ.

Correspondence concerning this article should be addressed to Marcelo Zeuli, Rua Marquês de São Vicente, 225-Gávea-Rio de Janeiro, Brazil. E-mail: marcelo.zeuli@bcb.gov.br; m_zeuli@yahoo.com.
} 
credibility. At the first look, the proposed VaR implementation of VaR seemed to be a general-purpose market risk analysis tool ${ }^{1}$

There were three motivations for this work. First of all, Abiad (2003) stated that there is a general consensus among economist that there is no methodology able to forecast crises with a high degree of accuracy. The second motivation and again considering Abiad (2003): Blejer and Schumacher (1998) did not empirically test their methodology ${ }^{2}$. Third, as Blejer and Schumacher (1998) stated, the vulnerability analysis should not only deal with the Central Bank traditional operations, but with all assets that compose its portfolio, including the derivatives. Therefore, the mark-to-market currency exchange swaps series that form the prices of the currency exchange swaps contracts of the portfolio of the Brazilian Central Bank were examined in the empirical tests of a volatility-based VaR methodology. Analyzing the second semester of the year 2002 was especially important, as it was a turbulent period, when the currency exchange swaps contracts debt exceeded $40 \%$ of the total of the Brazilian internal debt in the end of this year.

However, a complete vulnerability analysis must include all the assets and liabilities of a country, with all the components of a Central Bank portfolio — such as the international reserves and the treasury portfolio.

The volatility-based VaR methods became very popular in the 1990s, the time when the Riskmetrics ${ }^{\mathrm{TM}}$, from the J. P. Morgan Bank (1996), came out. The variance is usually modeled with Generalized Autoregressive Conditional Heteroscedasticity (GARCH), in order to capture the heteroscedasticity of the conditional variance of the financial series, a stylized fact known since Engle (1982) and Bollerslev (1986). Nevertheless, Fraga, Goldfajn, and Minella (2003, pp. 22-29) noted that, as usual in an Emerging Market Economy (EME), Brazil was subject to sudden stops in capital flows. Consequently, a regime-switching feature was incorporated in the models, and previously determined the various unconditional variance levels with the Iterative Cumulative Sum of Squares (ICSS) algorithm.

In the bibliographic review, there is a brief revision of the econometric financial models up to the Markov-Switching-Generalized Autoregressive Conditional Heteroscedasticity (SWGARCH) models.

In the tests and results chapter, in the first step, were identified several changes in the unconditional volatility of the daily returns of the series and the possible political and/or economical events associated to the change points. In the second step, the variances of the daily returns series were fitted to regime switching and to regime switching/ARCH models.

The results confirmed that there are two stylized facts that shall be taken into account: heteroscedasticity in the conditional variance and regime switching in the unconditional variance. The SWGARCH models were conceived to describe the series with those properties. However, the several unconditional volatility levels found in the daily returns of the currency exchange swaps series led to a problem of lack of parameter parsimony: even the three-regime models - each one with 20 coefficients—seemed to be not adequate to describe variances with so many changing points and such high levels. On the other hand, a volatility-based VaR do not necessarily generate forward-looking indicators, but rather coincident indicators of financial

\footnotetext{
${ }^{1}$ According to Abiad (2003), the VaR methodology “... is developed in detail, but Blejer and Schumacher refrain from estimating the model using existing data...". Nowadays, several Central Banks utilize VaR, as the Brazilian Central Bank for managing its foreign exchange reserves. See IMF (2005).

2 In the words of Blejer and Schumacher, even though: “... Most of the arguments regarding central bank’s commitment to defend a nominal regime have referred to the maintenance of a nominal exchange rate peg (such as fixed rate, a crawling peg, or a nominal band)... the analysis... could be equally applied to the assessment of the capability of the monetary authorities to support any other type of nominal regime”.
} 
vulnerabilities, as the high levels of the unconditional variance coincided with the beginning of some emerging markets crises.

\section{Bibliographic Review}

In the year 1998, International Monetary Fund (IMF) was the center of attention due to the Asian crisis (1997), in respect of which it was accused of not having previously detected any sign. Since then, simultaneously and in a complementary way to the development of the standards and codes approach ${ }^{3}$, the Fund has constantly concerned itself with developing Early Warning Systems (EWS), or systems capable of identifying ex-ante signs of economic crises. As indicated by Dornbush (1998), the understanding of recent crises requires a change of analytical approach, exchanging sustainability for vulnerability: "The moment the focus shifts from sustainability to vulnerability the whole discussion changes. Then the focus is on the bad scenario and just how bad it might be”.

The simple and popular VaR: in the words of Mendes (2004, p. 61), VaR "is usually defined as a possible loss that could occur to a portfolio on a horizon of T days, with small probability, in general 5\% or 1\%”. For parametric distributions, according to Jorion (1998, p. 87), "VaR is simply a multiple of standard-deviation of distribution, multiplied by a factor of adjustment that is directly related to the level of confidence”. Thus, VaR is a risk measure, which can be formally defined as:

$$
\operatorname{probability}\left(X_{t} \leq \operatorname{VaR}\right)=\alpha
$$

where $X_{t}=$ Random variable that represents the loss or profit.

Loss or profit associated with the portfolio of an institution, if held for a period $t$ (holding period), and $\alpha$ is the significance level, chosen in the interval (0.1) so that the probability of the portfolio realizing a loss superior to $\mathrm{VaR}$ if maintained for a period $t$ is equal to $\alpha$. From Blejer and Schumacher (1998, p. 8), there is a simple example of $\mathrm{VaR}$, calculated through the historical simulation method.

How to evaluate the portfolio risk: A simple and most used procedure to calculate the VaR of a portfolio is the delta-normal method or standard variance-covariance model. The asset price changes are conditionally normally distributed. The VaR portfolio is a linear combination of normal variables and is also normally distributed. The 2-assets portfolio VaR is:

$$
\operatorname{VaR}_{p}=\left[\left(\operatorname{VaR}_{1}\right)^{2}+\left(\operatorname{VaR}_{2}\right)^{2}+2 \times \operatorname{VaR}_{1} \times \operatorname{VaR}_{2} \times \rho_{1,2}\right]^{1 / 2}
$$

where $V_{a} R_{1}$ and $V a R_{2}$ are each asset's $\mathrm{VaR}$ and $\rho_{1,2}$ is the correlation-generally a Pearson's correlation—between assets 1 and 2.

Applying VaR to default analysis: Blejer and Schumacher (1998, p. 17) suggested a default probability function: $\pi$ (default) $=f(\operatorname{VaR} / V), f^{\prime}>0$; where: $V$ is the asset value. ${ }^{4}$

\section{Econometric Models: From Random Walk to GARCH Models}

For a long time the consensus prevailed that the stochastic processes associated with the financial series

\footnotetext{
${ }^{3}$ For a brief discussion of the standard and codes approach, see Berg, Borezstein, and Patillo (2004) and IMF (2004). From the latest: “... after the crisis in emerging market economies in the late 1990s, the adoption of internationally recognized standards, or codes of good practice, was seen as a way to help strengthen the international financial system...".

4 Dornbusch (1998) and Blejer and Schumacher (1998) suggested the applicability of VaR to macroeconomic questions: "Dornbusch (1998) suggests that members of the IMF should be required to put in place some sort of VaR analysis 'for the entire country' and that they should be monitored by the Fund, disqualifying for financial support those countries that are found deficient”.
} 
could be modeled through linear processes, almost always by random walk models. The autocorrelation and partial autocorrelation functions did not present sufficient evidence to reject the null hypothesis of acceptance of these models. Brock, Hsieh, and LeBaron (1992) noted that, before the advent of the non-linear dynamic, the tests of coefficients of autocorrelation gave the guarantee of linear independence, even though not guaranteeing non-linear independence. According to Rabi Jr. (1996), in the beginning of the 1980s the focus changed, when the non-linear models began to gain acceptance and when the Autoregressive Conditional Heteroskedasticity (ARCH) and GARCH models appeared, as well as the models of segmented trends and of chaotic dynamics. According to Brock et al. (1992), the most common reasons for deviations from the random walk model, as far as it affects the return of shares, are the volatility clustering and the calendar anomalies (for example, the weekend effect). The volatility clustering has been known for a long time, at least since when Mandelbrot (1963) concluded that, “... Great changes tend to be followed by great changes, whatever the signal may be, and small changes tend to be followed by small changes...".

The presence of volatility clustering in a series is an unmistakable sign of heteroscedasticity. Brock et al. (1992) stated that this led to the development of the ARCH and GARCH models.

The ARCH model developed by Engle (1982), has an autoregressive structure in the conditional variances of the returns. This allows shocks of volatility to continue in time. The conditional variance is a linear function of the square of past innovations. An ARCH (1) model can be represented by:

\section{Equation 1: Standard ARCH Model}

$$
R_{t}=\varphi_{0}+\varphi_{1} \cdot R_{t-1}+\varepsilon_{t}(A R(1) \text { Model })
$$

$$
\text { (1) } R_{t}=\Omega_{t-1}+\sim F\left(\mu_{t}, v_{t}\right) \text {; (2) } \varepsilon_{t} \sim N\left(0, v_{t}\right) \text {; (3) } \mu_{t}=\varphi_{0}+\varphi_{1} \cdot R_{t-1} \text {; (4) } v_{t}=\alpha_{0}+\sum \alpha_{i} \varepsilon_{t-1}^{2} ; i=1, \ldots, p
$$

where: $R_{t}$ is the price change (return) at time $t, \Omega_{t-1}$ stands for all the information available in the period, $p>0$ is the order of process, $\alpha_{0}>0, \alpha_{i} \geq 0$, and $F\left(\mu_{t}, v_{t}\right)$ is the conditional distribution of returns of conditional average $\mu_{t}$ and conditional variance $v_{t}$.

In 1986, Bollerslev proposed the GARCH model: the volatility of returns depends on the squares of precedent errors and precedent variances.

$$
v_{t}=\alpha_{0}+\sum_{i=1, \ldots p} \alpha_{i} \varepsilon_{t-i}^{2}+\sum_{j=1, \ldots q} \beta_{j} v_{t-j} ; q \geq 0 ; \beta_{j} \geq 0
$$

The inclusion of information regarding past variances allows sensibility to the volatility clusters and allows (Barcinski, Du, Almeida, Garcia, \& Silveira, 1997), that shocks in returns extend indefinitely in the future ${ }^{5}$.

Limitations of the GARCH models. The ARCH and GARCH models were conceived do deal with a single variance regime. By regime is understood that a constant or unconditional level of measure, e.g., average or variance/standard deviation/volatility—keeps unchanged, so that a change in regime implies a change level. However, these models only reflect one series of coefficients for one equation of returns and one equation of volatility. For Lamoureux and Lastrapes (1990) and Leal (1998), the use of GARCH is subject to error when sudden changes in variance occur, suggesting the introduction of dummy variables for each change of variance

\footnotetext{
${ }^{5}$ As Jorion (1998, p. 165) considered, “... the beauty of this specification is that it permits a parsimonious model, with few parameters, which appears to be very adequate for financial data... ”- data that systematically presents volatility clusters—even considering the non-linearity of the series and the necessity to estimate the parameters through likelihood.
} 
identified ex-post, or visually by the detection of outliers:

$$
v_{t}=\alpha_{0}+\alpha_{1} \varepsilon_{t-1}^{2}+\beta_{1} v_{t-1}+\alpha_{2} \varepsilon_{t-1}^{2} L \ldots+d_{1} D_{1}+\ldots+d_{k} D_{K}
$$

where $D_{1}, \ldots, D_{K}$ are dummy variables and $L$ stands for the leverage effect. Like Leal (1998), the algorithm of Inclán and Tiao (1994) is used to detect the changes in the unconditional variance. Table 1 has some ARCH and GARCH examples.

Table 1

ARCH and GARCH Examples

\begin{tabular}{|l|l|l|}
\hline Model & Returns equatiom & Variance equation \\
\hline ARCH & $R_{t}=\phi_{0}+\phi_{1} R_{t-1}+\varepsilon_{t}$ & $v_{t}=\alpha_{0}+\Sigma \alpha_{i} \varepsilon_{t-\mathrm{i}}^{2}, i=1, \ldots, p$ \\
\hline GARCH & $R_{t}=\phi_{0}+\phi_{1} R_{t-1}+\varepsilon_{t}$ & $v_{t}=\alpha_{0}+\Sigma \alpha_{i} \varepsilon_{t-\mathrm{i}}^{2}+\Sigma \beta_{j} v_{t-j} ; i=1, \ldots, p$ and $j=1, \ldots, q$ \\
\hline IGARCH & $R_{t}=\phi_{0}+\phi_{1} R_{t-1}+\varepsilon_{t}$ & $v_{t}=\alpha_{0}+\Sigma \alpha_{i} \varepsilon_{t-i}^{2}+\Sigma\left(1-\alpha_{j}\right) v_{t-j} ; i=1, \ldots, p$ and $j=1, \ldots, q$ \\
\hline GARCH-M & $R_{t}=\phi_{0}+\phi_{1} R_{t-1}+\varepsilon_{t}+\delta \sqrt{v_{t}}$ & $v_{t}=\alpha_{0}+\Sigma \alpha_{i} \varepsilon_{t-i}^{2}+\Sigma \beta_{j} v_{t-j} ; i=1, \ldots, p$ and $j=1, \ldots, q$ \\
\hline E-GARCH & $R_{t}=\phi_{0}+\phi_{1} R_{t-1}+\varepsilon_{t}$ & $\ln \left(v_{t}\right)=\alpha_{0}+\Sigma\left(\alpha_{i}\left|Z_{t-1}\right|+\gamma_{i} Z_{t}\right)+\Sigma \beta j \ln \left(v_{t-j}\right) ; i=1, \ldots, p$ and $j=1, \ldots, q$ \\
\hline Inclán/Tiao & $R_{t}=\phi_{0}+\phi_{1} R_{t-1}+\varepsilon_{t}$ & $v_{t}=\alpha_{0}+\beta_{1} v_{t-1}+\alpha_{1} \varepsilon_{t-1}^{2}+d_{1} D_{1}+\ldots+d_{k} D_{k}$ \\
\hline
\end{tabular}

where: $v_{t}$ is the conditional variance at time $t ; \varepsilon_{t} \sim N\left(0, v_{t}\right)$ means that the innovations are supposed to follow normal density with zero average and $v_{t}$ variance; the conditional average at time $t$ is: $\mu_{t}=\phi_{0}+\phi_{1} R_{t-1} ; p>0$ (and $q>0$ ) is (are) the order(s) of ARCH and GARCH process/processes; $\alpha_{0}>0, \alpha_{i} \geq 0$, and $\beta_{j}>0$. And IGARCH stands for integrated GARCH (Riskmetrics ${ }^{\text {TM }}$ ), GARCH-M for GARCH in Mean and the E-GARCH includes the leverage effect.

Time series subject to changes in regime. The departure point for reviewing regime switching is Hamilton (1990), who applied the estimation maximation (EM) algorithm for parameter estimation through maximum likelihood estimation (MLE) ${ }^{6}$. Hamilton and Susmel (1994) and Cai (1994) introduced the SWARCH (Switching ARCH) models, a generalization of the ARCH model of Engle (1982), which allows discrete changes in its level parameters through a Markov process. The presumed next step in evolution is the SWGARCH model. However, due to path dependencies - in the first specifications, like Gray's (1996), the GARCH variance was dependent to the entire history of regimes-Hamilton and Susmel (1994) and Cai (1994) stayed with the SWARCH models.

The SWGARCH models combine GARCH with regime switching. In the model specification, from Haas, Mittnik, and Paolella (2004, p. 497), the regime variances only depend on past shocks and their own lagged values - the path-dependency restriction was removed. This specification is analytically treatable, allows a separation of the process of conditional variance and offers direct parameter estimation through maximum likelihood.

\section{Equation 2: SWGARCH Model-Haas et al. (2004)}

Average: $y_{t}=\mu_{s t}+u_{t}$; Residuals: $u_{t}=\sqrt{v_{t}} \varepsilon_{t}$; Either $\varepsilon_{t} \sim N\left(0, \sigma_{s t}\right)$ or $\varepsilon_{t} \sim t-$ student .

The conditional variance equation for the SWGARCH models $(k, p, q)$-L is:

\footnotetext{
6 The EM-algorithm can be adapted to non-normal distributions and yields maximum likelihood estimates of the model parameters. These estimates are consistent, unbiased and efficient (see Dempster, Laird, \& Rubin, 1977).
} 


$$
v_{t, k}=\alpha_{0}+\sum_{i=1}^{q} \alpha_{i} u_{t-1}^{2}+\sum_{j=1}^{p} \beta_{j} v_{t-1, k}+\xi d_{t-1} u_{t-1}^{2}
$$

where $v_{t, k}$ stands for the $k$-regime variance at period $t, \alpha_{0}, \alpha_{i}, \beta_{j}$ and $\xi$ are constant and $d_{t-1}$ stands

for the leverage effect: $d_{t-1}=1$ if $u_{t} \leq 0$ and $d_{t-1}=0$, otherwise.

Extreme value theory. Authors like Blejer and Schumacher (1998, p. 24), Schachter (1997), Vieira Neto and Urban (2001), and Monteiro and Silva (2002), recognized the need to complement VaR with stress tests based on the extreme value theory. However, the existence of pre-determined oscillation limits for the currency exchange swaps series are established in the swap contracts. Consequently, EVT does not apply, since the maximum daily prices fluctuations are deterministic.

Correlations. The second basic component of the standard variance-covariance model is the correlation between changes in price of the assets of a portfolio. Brooks and Persand (2000, p. 7) considered that a positive correlation between volatility and correlation represents, potentially, a great problem for VaR methodologies, as Jorion (1998, p. 173) stated ${ }^{7}$.

Leite and Sanvicente (1994, pp. 128-130) showed that, just after the 1987 crisis, the correlations between the stock markets became greater. Blejer and Schumacher (1998, p. 23) adopted a simple solution to this potential problem, by suggesting a unitary correlation value in turbulent times. ${ }^{8}$ However, this is cannot be treated as a stylized fact, since different results can be reached depending on the chosen correlation methodology. For EWMA correlations, the greatest values (in the module) did not occur in the same period of the greatest volatility.

\section{Methodology}

The methodologies utilized in this work were applied in two steps. In the first step, the Iterative Cumulative Sum of Squares (ICCS) algorithm was used to identify the changes in the unconditional variances of the daily returns of the series. In the second step the daily returns were modeled first only with regime switching and then with regime switching and heteroscedasticity, with SWARCH and SWGARCH.

Determining sudden changes in variance: The discrete changes in the unconditional variance were evaluated with the ICCS—algorithm developed by Inclán and Tiao (1994) ${ }^{9}$.

Once estimated the change points, the next step is to identify political and/or economical coincident events that could be responsible for changes in the level of unconditional volatility.

Regime switching (the EM algorithm): The Hamilton's (1990) model was adapted to estimate a 2 Markov state model, with average and variance being variables of a 1-dimension vector. Each series was tested individually. From the Markov chain properties, the duration of each regime can be easily derived. Defining $D$ as the duration of a specific regime, $S_{t}$ the state variable at time $t, j$ a index that stands for the regime $j, p_{j j}$ the probability of staying in the same regime $j$ from time $t$ to time $t+1$.

\footnotetext{
7 The increases in correlations during the periods of elevation of volatility, invalidate the properties of diversification of portfolios... it is frequently argued that the correlations increase in periods of global turbulence...

${ }^{8}$ Although the calculation of the VaR with partial correlations can make economic sense in a stable scenario, it should be considered that in scenario of crises or contagion, most correlations would tend to be close of unity.

9 The ICCS program was written by Inclan (08/1994) in the Regression Analysis of Time Series (RATS) language, version 4.3.0. See Fernandes and Monteiro (1997) and Leal (1998), for other examples of the applicability of the ICCS algorithm to Brazilian financial series.
} 


\section{Equation 3: Expected Regime Duration}

Duration $=1$ : if $S_{t}=j$ and $S_{t+1} \neq j ; P[D=1]=\left(1-p_{j j}\right)$;

Duration $=2$, if $S_{t}=j, S_{t+1}=j$ and $S_{t+2} \neq j ; P[D=1]=p_{j j}\left(1-p_{j j}\right)$. Then, by induction:

$$
E(D)=\sum_{j=1}^{\infty} j P[D]=\left(1-p_{j j}\right)+2 \cdot p_{j j} \cdot\left(1-p_{j j}\right)+3 \cdot p_{j j}^{2} \cdot\left(1-p_{j j}\right)+\ldots=\frac{1}{1-p_{j j}}
$$

SWARCH: the SWARCH (Switching ARCH) models from Hamilton and Susmel (1994) were utilized in the first tests, yet discarded on behalf of the parsimony of the SWGARCH models.

SWGARCH: the SWGARCH models in this work were based on Haas et al. (2004) and on Valls and Almeida (2000). Each series was modeled with a univariate SWGARCH model, with GARCH $(1,1)$. The volatility equation is described below.

Equation 4: Variance Equation According to Haas (2004)

$$
v_{t, k}=\alpha_{0}+\sum_{i=1}^{q} \alpha_{i} u_{t-1}^{2}+\sum_{j=1}^{p} \beta_{j} v_{t-1, k}+\xi d_{t-1} u_{t-1}^{2}
$$

where $v_{t, k}$ stands for the $k$-regime variance at period $t, \alpha_{0}, \alpha_{i}, \beta_{j}$, and $\xi$ are constant and $d_{t-1}$ stands for the leverage effect: $d_{t-1}=1$ if $u_{t} \leq 0$ and $d_{t-1}=0$, otherwise.

\section{Series}

The portfolio of the internal Brazilian debt, in 2002, included two types of contracts indexed to the currency: the currency exchange swaps, negotiated in the BM\&F IBOVESPA (Brazilian Mercantile \& Futures Exchange), and the NTN-D (National Treasury Notes—series D). According to Meirelles (2004), the Central Bank's currency exchange swap were offered to the market “... at the height of the confidence crisis ... through which the country passed in the second semester of 2002”.

The Mark-to-Market currency exchange swap series began in August of 1999. The Central Bank currency exchange swaps contracts began to be negotiated in April 2002, with a monthly adjustment of positions. From June 2002, the adjustment became daily. From July 2002, three types of contracts were established: contracts SCC, SC2, and SC3. Contracts type SCC and SC3 were daily adjusted. The number of contracts was over than 200 the period from mid-July 2002 to August 2002, and the total financial volume surpassed US\$30 billion.

Underlying asset. The underlying asset is the spread between the interest rate and the exchange rate variation, defined as follows:

(1) The interest rate of Interbank Deposits (ID), defined as the capitalized daily average of one-day ID rates, calculated by the Central of Custody and Financial Settlement of Securities (CETIP) and verified in the period between the trading day and the day preceding the expiration date;

(2) The exchange rate variation, measured by the offered exchange rate of Brazilian Reais per United States Dollar for cash delivery traded in the free rate foreign exchange market.

Swaps with daily adjustment. The daily adjustment of a contract is the difference between the position "carried over" from the previous day-Previous Day's Updated Value (PUV)—and the market quotation-Mark-to-Market PU (MTM PU). It is credited to the holder of the position of a long nature (buyer), and debited to the holder of the position of a short nature (seller). This pricing rule agrees with Jorion (1998, p. 128): one of the general swaps characteristics is the pricing form that accounts for the difference between the 
present value of the asset cash flow and the present value of the liability cash flow. A contract is defined according to its notional value (either US\$50,000 or US\$1,000) and term.

Example: contract SCC/K307. Type SCC contracts have the size of US\$50,000.00 (fifty thousand US dollars) of final value. The letter K means the month of May. The number 3 stands for the year of 2003 and 07 stands for the seventh day of the month. Therefore, the contract's term is January 22, 2003, with U\$50,000.00 of final value. Tables 2 and 3 exemplify these examples.

Table 2

Mnemonic Rule for Currency Exchange Swaps (Month of Maturity)

\begin{tabular}{|l|l|l|l|l|l|l|l|}
\hline Letter & Month & Letter & Month & Letter & Month & Letter & Month \\
\hline F & January & J & April & N & July & V & October \\
\hline G & February & K & May & Q & August & X & November \\
\hline H & March & M & June & U & September & Z & December \\
\hline
\end{tabular}

Table 3

Currency Exchange Swap Negotiation Units

\begin{tabular}{ll}
\hline Type & Value \\
\hline SCC & US $\$ 50,000.00$ (fifty thousand US dollars) Final Value \\
SC2 & US $\$ 1,000.00$ (one thousand US dollars) Final Value \\
SC3 & US $\$ 1,000.00$ (one thousand US dollars) Final Value \\
\hline
\end{tabular}

From the BM\&F website, 45 mark-to-market currency exchange swaps rates series were extracted, each one with a specific time to maturity. The MTM swaps rates were interpolated in order to calculate the daily rate and daily unit price (PU) of each contract and then the adjusted positions were generated. A set of four-type series was generated: Currency Exchange Swaps rates (Mark-to-Market values and adjusted values) and Currency Exchange Swaps prices (Mark-to-Market values and adjusted values). The next section test and show the results for the 90 Mark-to-Market returns series.

\section{Tests and Results}

Identification of Changes in the Volatility Regime: the daily returns of the Mark-to-Market rates and the Mark-to-Market rates prices series were calculated ${ }^{10}$. The daily frequency was chosen because most of the currency exchange swap contracts were adjusted on a daily base. The return equation is:

\section{Equation 5: Equation of Returns}

$$
\text { Return }=R_{t}=L N\left(\frac{X_{t}}{X_{t-1}}\right)
$$

where $X_{t}=1+$ (effective annual rate/100), for rates or $X_{t}=$ Price Unit at time $t$, for prices.

The IBOVESPA share index and the daily spot Reais per dollar exchange value (R\$/US\$, code PTAX) were also tested, in a total of 92 series. The hypothesis of normal distribution of returns was rejected for all series but for the IBOVESPA index, through the Kolmogorov-Smirnov test. The presence of heteroscedasticity was evident in all currency swaps series, as they showed significant autocorrelation between the lagged square returns. After generating the daily returns series, the next step was defining an AR (1)-GARCH $(1,1)$ to model the returns series. As following Leal (1998) stated.

${ }^{10}$ Generally, the returns series are the focus of the ARCH and GARCH models (see Shumway \& Stoffer, 2000). 


\section{Equation 6: AR/GARCH Equations for the Returns Series}

$$
R_{t}=\varphi_{0}+\varphi_{1} \cdot R_{t-1}+\mu_{t}(A R(1) \text { Model }) ; \quad v_{t}=C+P v_{t-1}+Q \cdot u_{t-1}^{2}+L e v \cdot I_{t-1} \cdot u_{t-1}^{2}
$$

where: $u_{t}=\left(v_{t}\right)^{0,5} e_{t} ; e_{t}=t\left(\mu=0 ; \sigma^{2}=1 ; d . f .=D\right)\left(t\right.$-student Distribution); $I_{t}=1$ if $u_{t}<0$ and $I_{t}=0$ if $u_{t} \geq 0$; the coefficient $\phi_{1}$ is the $\operatorname{AR}(1)$ coefficient in the equation of returns; $\phi_{0}$ is the constant coefficient in the equation of returns; $C$ is the constant coefficient in the conditional variance equation; the residuals $u_{t}$ are linked to the volatility $\left(u_{t}=\left(v_{t}\right){ }^{0,5} e_{t}\right)$; $Q$ is the order of displacement of residuals; $P$ is the order of displacement of conditional variance; $L e v$ is the coefficient of the leverage effect; and $D$ is the number of degrees of freedom of the $t$-student distribution that models the series of returns.

In the next step, the residuals were analyzed through the ICSS algorithm in order to identify the levels of unconditional variance/volatility and its change points.

Associating sudden changes in the unconditional volatility with outstanding events. All the daily returns series presented at least eight change points in the unconditional volatility. Taking the daily returns of the 30-days to maturity currency exchange swap rate as reference, political and/or economical events could be responsible for the changes in the unconditional volatility of the daily returns series. Figure 1 and Table 4 show some possible “candidates” for crucial events.

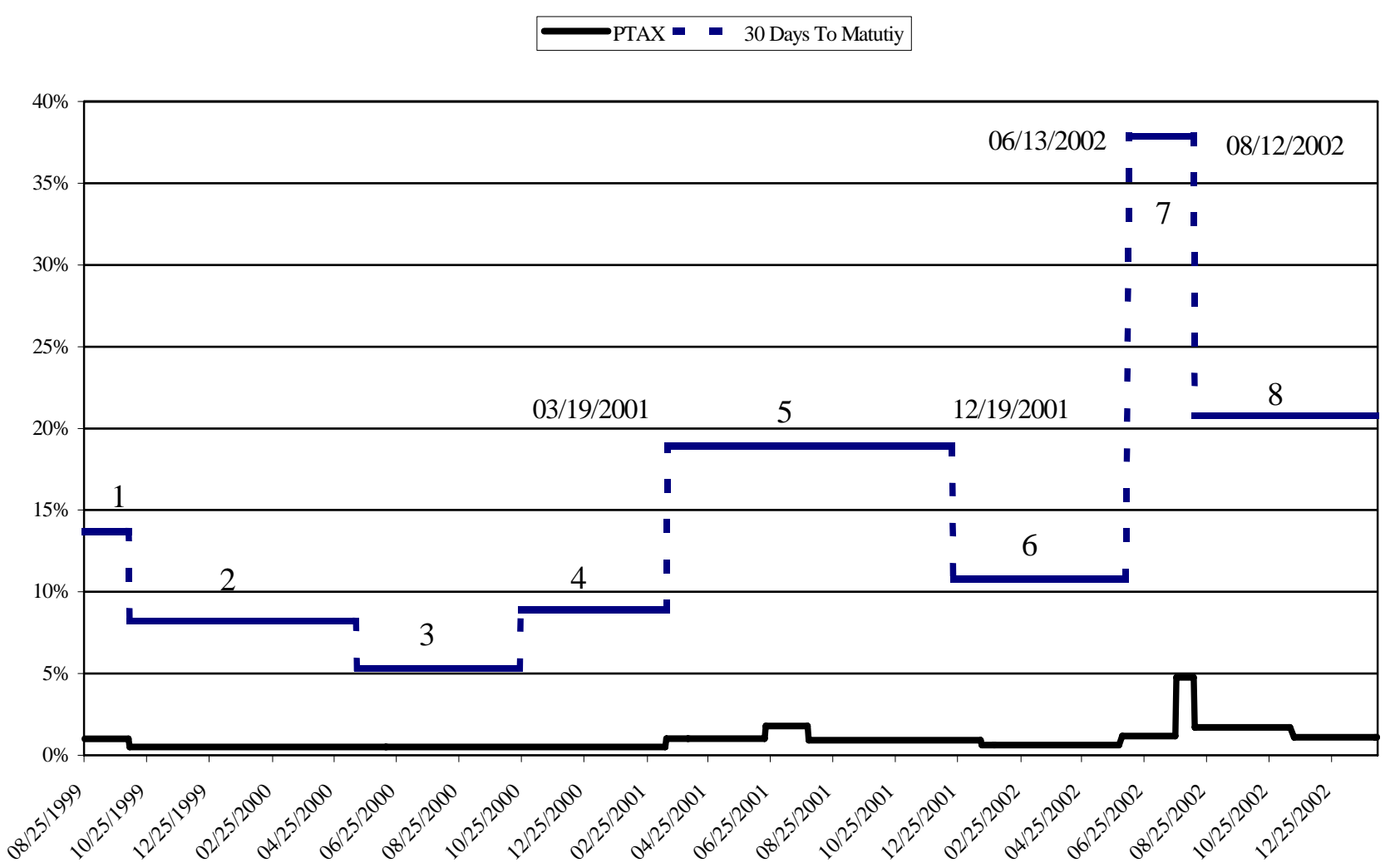

Figure 1. Unconditional volatility of the daily returns of the currency exchange swaps rates. Notes. (1) PTAX - currency exchange rate (US\$/Brazilian REAIS), daily closing prices; (2) currency exchange swaps taxes (US\$/Brazilian REAIS) for 30 days to maturity term; and (3) For a lower volatility, please evaluate with currency exchange swaps prices instead of taxes. 
Table 4

Sudden Changes in the Unconditional Volatility Due to Political or Economical Events

\begin{tabular}{lllll}
\hline $\begin{array}{l}\text { Thirty days to } \\
\text { maturity currency } \\
\text { swap / periods }\end{array}$ & From & To & $\begin{array}{l}\text { Standard } \\
\text { deviation (\%) }\end{array}$ & Possibilities \\
\hline 1 & $08 / 25 / 1999$ & $10 / 07 / 1999$ & 13.70 & Initial phase of currency float regime (Brazil) \\
2 & $10 / 08 / 1999$ & $05 / 16 / 2000$ & 8.19 & COPOM $^{11}$ : 40th meeting kept basic interest rate at 19\% per year \\
3 & $05 / 17 / 2000$ & $10 / 23 / 2000$ & 5.31 & Lull period \\
4 & $10 / 24 / 2000$ & $03 / 15 / 2001$ & 8.92 & Argentine crisis, Turquish crisis, high Petroleum spot prices \\
5 & $03 / 16 / / 2001$ & $11 / 19 / 2001$ & 18.91 & Argentine's default, energy crisis, 911 \\
6 & $12 / 20 / 2001$ & $07 / 07 / 2002$ & 10.80 & Beginning of Presidential Campaign (Brasil) \\
7 & $06 / 10 / 2002$ & $08 / 12 / 2002$ & 37.88 & Confidence crisis, auction/conversions among currency papers \\
8 & $08 / 13 / 2002$ & $02 / 06 / 2003$ & 20.77 & (SC2 for SC3) \\
& & & & Glection's Eve, IMF Stand-by Loan and beginning of Lula's \\
\hline
\end{tabular}

In 1999, the unconditional volatility dropped from October, a consequence of an internal and external political and economical environment that was little disturbed in comparison with the end of 1998 (Russian crisis) and the beginning of 1999 (Brazilian currency crisis).

The year 2000 was characterized by lull in the Brazilian scenario, despite the "burst" of the "DOT.COM bubble". At the end of this year, signs of crisis in Turkey and Argentina were detected-a significant increase in the volatility of the main share indexes of both countries - and the oil prices rose significantly in the world spot market. These signs of crisis presumably generated the fear of possible contagion of the Brazilian economy.

In 2001, the unconditional volatility of the daily returns of the 30-day to maturity swaps 30-raised to almost 9\% on March 15, when the Argentine default became seen as probable. In this same period an energy crisis occurred in Brazil—with "black-outs" and with the government campaign for rationing energy—together with a political crisis. To close the year with great impact, the United States suffered the terrorist attacks (911).

In the second semester of 2002, the volatility of the Brazilian financial series was determined by the election campaign. The fundaments of the economy were considered solid, for example, by Razin and Sadka (IMF, 2004), who identified the elections and the expected change of political and economical regime as being the two triggers of the Brazilian crisis-a confidence crisis, in the words of Meirelles (2004). In our point of view, it would be not possible for a model tested with data before the second semester of 2002 to forecast the jump of the volatility levels since June 2002. The Mark-to-Market currency exchange swaps prices raised to high levels in the unconditional volatility from August 2002. However, possibly those high levels appeared not only due to the confidence crisis, but also to the increase in the number of currency swap contracts and to the large volume of conversions of contracts without daily adjustment (SC2) for contracts with daily adjustment (SC3). The volatility decreased by August 13, 2002, possibly as a result of the announcement of the IMF stand-by loan, yet not returning to the former levels before June 2002.

The currency exchange rate (Brazilian Reais per United States Dollars) raised to almost R\$ 4/US\$ on October 22, 2002, the eve of the second round voting of the presidential elections, and its unconditional volatility was greater than the volatility by the time of the Brazilian currency crisis (January 1999). Those

11 COPOM: the Brazilian Monetary Policy Committee. 
happened to be the historic maximums since the creation of the real currency, in July 1994.

Considering the daily returns of the currency exchange swaps prices, Figure A1 (see Appendix A) shows that the peak unconditional volatility was almost the same-near 8\%—at the same time-August 8, 2002-to all series. At that time, the daily price fluctuations were set by contract to a maximum value near $7.5 \%$. This fact shows that the peak volatilities were coherent with the pre-established oscillation limits ${ }^{12}$. That is a reason for bypassing the EVT tests, since the daily price oscillations were deterministic.

Identification of persistence according to Diebold. When modeling the daily returns of the currency exchange swaps series with GARCH $(1,1)$, all series showed high persistence, with the sum of the ARCH and GARCH coefficients being even greater than one in some of them. This result suggested the existence of changes in the unconditional variance regime, in accordance with Diebold (1986).

Regime switching, VaR, and default function. All series showed a considerable number of changes in the unconditional variance. The algorithm EM was adapted from Hamilton (1990) ${ }^{13}$ in order to test the daily returns series with a two-regime model. The average of the daily returns was modeled, with the random component following a normal distribution with zero average and variance following a GARCH process. Next, the VaR and an expected loss function for each individual daily returns series were calculated.

\section{Equation 7: Simple Model With Regime Switching-Hamilton (1990)}

$$
y_{t}=\mu_{s t}+\varepsilon_{t}, \varepsilon_{t} \sim N\left(0, \sigma_{s, t}\right)
$$

Expected loss function. Blejer and Schumacher (1998, p. 17) suggested a default probability function: $\pi$ (default) $=f(\mathrm{VaR} / V) ; f^{\prime}>0$ and $V$ is the value of the asset. The expected loss is defined as $\mathrm{VaR} / V$, being $\mathrm{VaR}$ proportional to the daily volatility of regime $s$ at day $t$. The holding period was set to unity (one day), instead of the usual 10-day holding period, considering that in many simulations the daily returns series showed durations lower than three days. This leads to establish expected daily loss equations (see equation 8).

Equation 8: Expected Daily Loss Evaluated From Currency Exchange Swap Rates

$$
\frac{\text { VaR }}{\text { Value }}=\left(S F \times M T M_{t} \times \sigma_{s, t} \times \frac{P_{i}}{252}\right) / M T M_{t}=S F \times \sigma_{s, t} \times \frac{P_{i}}{252}
$$

where: $P_{i}$ : days to maturity of the series; $\sigma_{s, t}=$ volatility of regime $s$ at day $t ; S F$ : Sensibility Factor. $S F=2.33$ (for a $1 \%$ significance level) and $M T M_{t}$ is the Mark-to-market value of the contracted currency exchange swaps at day $t$. Concerning to the currency exchange swap prices (PUV and MTM PU), the equation is simplified to the product of the volatility and the sensibility factor (SF).

\section{Equation 9: Expected Daily Loss Evaluated From Currency Exchange Swap Prices}

$$
\frac{V a R}{\text { Value }}=\left(S F \times M T M_{t} \times \sigma_{s, t}\right) / M T M_{t}=S F \times \sigma_{s, t}
$$

Table 5 exhibits some results. The values P1 and P2 are the probabilities of staying in the same regime from time $t$ to time $t+1$. The durations (low and high volatility durations) are the estimated days in for staying in the same regime. The daily loss columns followed equation 9.

\footnotetext{
12 Minimum price fluctuation: 0.01 of an interest rate point. Maximum daily price fluctuation: A percentage established by $\mathrm{BM} \& \mathrm{~F}$ based on the market rate of the ID $\times$ U.S. Dollar spread corresponding to the time to maturity of the series.

${ }^{13}$ See the following program, available on the author's web page: ftp://weber.ucsd.edu/pub/jhamilto/markov2.zip.
} 
Table 5

Daily Returns of Currency Exchange Swap Prices: With Two-Regime Volatility ${ }^{14}$

\begin{tabular}{lllllllll}
\hline $\begin{array}{l}\text { Days to } \\
\text { maturity }\end{array}$ & P1 & P2 & $\begin{array}{l}\text { Low } \\
\text { volatility (\%) }\end{array}$ & $\begin{array}{l}\text { High } \\
\text { volatility (\%) }\end{array}$ & $\begin{array}{l}\text { Low } \\
\text { volatility } \\
\text { duration }\end{array}$ & $\begin{array}{l}\text { High } \\
\text { volatility } \\
\text { duration }\end{array}$ & $\begin{array}{l}\text { Low } \\
\text { volatility } \\
\text { daily loss (\%) }\end{array}$ & $\begin{array}{l}\text { High } \\
\text { volatility } \\
\text { daily loss (\%) }\end{array}$ \\
\hline 270 & 0.9725 & 0.9644 & 0.91 & 2.83 & 36.37 & 28.10 & 2.12 & 6.59 \\
300 & 0.9734 & 0.9661 & 0.82 & 2.57 & 37.54 & 29.51 & 1.92 & 5.99 \\
330 & 0.9734 & 0.9661 & 0.75 & 2.37 & 37.60 & 29.50 & 1.76 & 5.51 \\
360 & 0.9735 & 0.9661 & 0.69 & 2.19 & 37.71 & 29.52 & 1.61 & 5.11 \\
390 & 0.9744 & 0.9678 & 0.65 & 2.04 & 38.99 & 31.04 & 1.51 & 4.76 \\
420 & 0.9758 & 0.9700 & 0.61 & 1.92 & 41.32 & 33.31 & 1.41 & 4.47 \\
450 & 0.9762 & 0.9707 & 0.57 & 1.81 & 42.00 & 34.16 & 1.32 & 4.21 \\
480 & 0.9772 & 0.9714 & 0.54 & 1.74 & 43.84 & 34.91 & 1.27 & 4.06 \\
510 & 0.9785 & 0.9728 & 0.52 & 1.67 & 46.60 & 36.76 & 1.22 & 3.89 \\
\hline
\end{tabular}

The results are reliable, since in all tests for each series the EM algorithm converged to the same final values. The expected duration, with the exception of the 2,160 days to maturity currency swaps prices, was found of less than two months, which is a clear evidence of the instability of the economic and political environment in question.

Modeling with SWGARCH. The SWGARCH $(1,1)$ univariate models were tested for all the 92 series. The equations followed Haas et al. (2004) and Valls and Almeida (2000), ${ }^{15}$ with the coefficients defined after maximizing the log-likelihood of the SWGARCH parameters. Several volatility regimes could be tested (parameter $k$ ), yet for parsimony tests were restricted to three and two regimes. In each regime the coefficients $\mathrm{ARCH}$ and $\mathrm{GARCH}$ assumed distinct or equal values to the other regimes.

Each series was simulated with 50,000 at random combinations of parameters: two and three volatility regimes ( $k=2$ and $k=3$ ), $t$-student distributions for the innovations - with the degrees of freedom varying from 2 to 21-leverage effect and a complete probability transition matrix. Quite a few times the persistence-sum of the ARCH and GARCH coefficients - was under 0.6, a result in line with the results of the ICSS algorithm. Those results indicated that a larger number of states or levels of unconditional volatility could describe the daily returns series.

Most of the series were optimized with $t$-distributions with few degrees of freedom. Some series were optimized with 21 degrees of freedom, suggesting, in those cases, the adequacy of the normal distribution. For the MTM series with the longest term, the leverage coefficients were insignificant. The MTM series with terms of one day and 30 days presented negative likelihood, indicating that the modeling was inadequate.

Table 6 exemplifies the results of this section. The items V1, V2, and V3, stands for the low, medium, and high volatilities. P1, P2, and P3 are the respective persistences. The daily loss columns followed equation 9.

\footnotetext{
14 Probability, volatility, duration, and expected losses.

15 Professor Haas kindly provided a MATLAB source code program for SWGARCH models. The source code was added with the $t$-student distribution and the leverage effect.
} 
Table 6

Three-Regime SWGARCH With High Persistence (Daily Returns-Prices)

\begin{tabular}{lllllllllll}
\hline Series & $\begin{array}{l}\text { LOG of } \\
\text { likelihood }\end{array}$ & V1 (\%) & V2 (\%) & V3 (\%) & P1 & P2 & P3 & $\begin{array}{l}\text { Daily loss } \\
\text { V1 (\%) }\end{array}$ & $\begin{array}{l}\text { Daily loss } \\
\text { V2 (\%) }\end{array}$ & $\begin{array}{l}\text { Daily loss } \\
\text { V3 (\%) }\end{array}$ \\
\hline PTAX & 1,926 & 2.15 & 3.36 & 4.58 & 1.3 & 0.64 & 0.94 & 5.01 & 7.83 & 10.67 \\
1200 DTM $^{16}$ & 2,295 & 0.39 & 1.27 & 1.78 & 1.61 & 0.69 & 0.31 & 0.91 & 2.96 & 4.15 \\
1440 DTM $^{2,038}$ & 0.32 & 1.04 & 1.46 & 1.61 & 0.69 & 0.31 & 0.75 & 2.42 & 3.40 \\
1800 DTM & 1,990 & 0.02 & 0.75 & 1.07 & 0.53 & 0.91 & 0.35 & 0.05 & 1.75 & 2.49 \\
2160 DTM & 858 & 0.36 & 0.57 & 0.59 & 0.98 & 1.26 & 1.18 & 0.84 & 1.33 & 1.37 \\
2520 DTM & 779 & 0.35 & 0.56 & 0.58 & 0.98 & 1.26 & 1.18 & 0.82 & 1.30 & 1.35 \\
IBOVESPA & 1,322 & 1.53 & 1.61 & 1.97 & 0.61 & 0.7 & 0.23 & 3.56 & 3.75 & 4.59 \\
\hline
\end{tabular}

The duration of each volatility regime did not exceed seven days in any of the tested series. In other words, the probabilities of staying in the same regime from time $t$ to time $t+1$ were low. Once again, like the previous tests with a two-regime model, the results demonstrated an unstable scenario.

\section{Conclusions}

This work applied a VaR approach to evaluate a country financial vulnerability, by analyzing the risk exposure of its Central Bank, as if their assets are subject to market risk, according to Blejer and Schumacher (IMF working paper, 1998). The assets chosen for the tests were the derivatives of the Brazilian Central Bank portfolio, with source data extracted from the Brazilian Mercantile \& Futures Exchange (BM\&F) database. The chosen method was the delta normal VaR method, applied to the volatility of the daily returns of the currency exchange swaps rates and to the volatility of the daily returns of the currency exchange swaps prices, from August 1999 to January 2003.

In the first step of the results, various changes in the unconditional volatility in all the daily returns series were detected; in an average of nine levels for the currency exchange swaps rates and prices. When modeling the volatility with heteroscedasticity and regime switching-whether with SWARCH or SWGARCH models - the number of levels implied a non-parsimonious number of parameters. The existence of various regimes of variance, with non-zero transition probabilities between these regimes is not rejected. However, it is also appropriate to consider the hypothesis of the occurrence of various structural breaks, especially for the case of the brisk jumps in the unconditional volatility of the daily returns series at the second semester of 2002, when the so-called confidence crisis occurred.

Nevertheless, the SWGARCH models cannot be discarded as a good alternative to describe the volatility of the tested series. In future studies, test frequencies for the returns other than daily frequencies will be done, as well as other distributions of the returns, such as the generalized error distribution (GED). The transition probabilities may vary with time, instead of being deterministic. The regime switching approach from the SWGARCH models provides unbiased scenario choices, a better approach than the stress test models cited, for instance, in Jorion (1998, p. 189), since those models specify scenarios in a subjective way.

The empirical tests indicated the rejection of the hypothesis of the normal distribution of the daily returns and, consequently, the hypothesis of efficient markets, thus calling in doubt the applicability in our scenario of the standard delta-normal method. In our point of view, Blejer and Schumacher (1998) developed a pure econometric methodology, composed of two "boxes": the first "box" is a volatility-based implementation of the

${ }^{16}$ DTM: Days to Maturity. 
VaR financial concept, and the second "box" is an EVT-based stress test approach.

Concerning to the second "box", Blejer and Schumacher (1998) introduced it as a useful alternative to forecast discrete events. However, it is possible that a high volatility can be wrongly taken as an extreme value when, in fact, there are various possible high levels of unconditional volatility that can occur in relatively unstable economic and political scenarios, as in the Brazilian scenarios in the period 1999/2002. Beyond that, the real extreme values were the pre-determined price oscillation limits of the currency exchange swap contracts, specified according to the maximum daily oscillation established by BM\&F. In other words, the dimension of the impact was a priori established. On the other hand, the currency exchange swaps series are relatively recent (the first series started in August, 1999) and, therefore, have little historic content to help modeling extreme values. However, EVT tests are not discarded for future studies.

The results hardly recommend the use of volatility-based methodologies to identify forward-looking indicators of financial vulnerabilities, as those methodologies depend upon historical data. In our point of view, a high volatility is not necessarily a clear evidence of vulnerability. Rather, it is a general symptom. This symptom can be interpreted either as a symptom of a crisis or as a sign of a very brief economical or financial change, or even an evidence of a structural change. Abiad (2003) reported false crisis warnings that were originated from indicators utilized in several early warning systems, not to mention that discrete shifts between states-with a corresponding low and high variance-is a characteristic of business cycles, such as those described in Hamilton (1989).

When analyzing the economical scenario, the significant increase of the unconditional volatility of the daily returns of the currency exchange swap series can be associated to the start of some emerging markets crises, especially the Brazilian confidence crisis in the second semester of 2002. No evidence was found that these levels were predictable. In addition to this verification, the changes in the rules and clauses of the currency exchange swaps contracts could be also seen as co-responsible for the jump in the unconditional volatilities that occurred in August 2002. The raise of the unconditional volatility, therefore, had different sources. A high volatility—-together with a high VaR, if the assets correlations are set to unity—could be considered as a coincident indicator of the growing vulnerability of the evaluated Brazilian scenario. Concerning to the correlation estimation usually utilized in the delta normal method, the choice of the correlation—such as moving average of EWMA correlations-implied very different results, suggesting the evaluation of the financial copulas in future tests.

A mere visual inspection of the results confirmed that the high volatility of financial series is typical of emerging markets, as described in Bekaert and Harvey (1997). Nevertheless, the reader shall consider, like Morales and Schumacher (2003), that volatility implies different risks according to the environment ${ }^{17}$ —or even according to the referential or value judgment of the analyst.

The purpose of this work was to test, not to define a general market risk methodology, for Central Banks. However, some final comments apply. Taking the variance as the risk measure, a candidate for a general (market) risk model must incorporate two stylized facts concerning to the variance of financial series: autoregressive conditional heteroscedasticity (ARCH) and regime switching. Two difficulties for a generalization distinguished from this work: each asset has its own contract characteristics-eventually with

17 The same volatility indicator in an unstable environment would imply much less risk being undertaken relative to a calmer environment. 
alterable clauses - and the existence of scenarios with several and high levels of unconditional volatility that could generate non-parsimonious models.

The future research will evolve towards evaluating the effects of the Basel III recommendations as if they could be applied to this crisis period: the 2002 Brazilian confidence crisis.

\section{References}

Abiad, A. (2003). Early warning systems: A survey and a regime switching approach. Washington, D.C.: IMF.

Barcinski, A., Du, P., Almeida, B. C., Garcia, M., \& Silveira, M. A. C. (1997). Estimation of volatility return of Brazilian stocks:

An alternative method to GARCH family (Estimação da Volatilidade do retorno das Ações Brasileira: Um Método Alternativo à Família GARCH). Resenha $B M \& F, 116,21-39$.

Bekaert, G., \& Harvey, C. R. (1997). Emerging equity market volatility. Journal of Financial Economics, 43, 29-77.

Berg, A., Borezstein, E., \& Patillo, C. (2004). Assessing early warning system: How have they worked in practice? Washington, D.C.: IMF.

Blejer, M. I., \& Schumacher, L. (1998). Central bank vulnerability and the credibility of commitments: A value-at risk approach to currency crises (p. 39). IMF Working Paper, Washington, D.C..

Bollerslev, T. (1986). Generalized autoregressive conditional heteroskedasticity. Journal of Econometrics, 31, 307-327.

Brock, W., Hsieh, D., \& LeBaron, B. (1992). Nonlinear dynamics, chaos, and instability: Statistical theory and economic evidence (pp. 82-129). Cambridge: The MIT Press.

Brooks, C., \& Persand, G. (2000). Value-at-risk and market crashes. Journal of Risk, 2(4), 5-26.

Cai, I. (1994). A markov model of switching-regime ARCH. Journal of Business and Economic Statistics, 12, 309-316.

Dempster, A. P., Laird, N. M., \& Rubin, D. B. (1977). Maximum likelihood from incomplete data via the EM algorithm. Journal of the Royal Statistical Society, 39, 1-8.

Diebold, F. X. (1986). Modeling the persistence of conditional variances: A comment. Econometric Reviews, 5, 51-56.

Diebold, F. X., \& Lopez, J. A. (1996). Modeling volatility dynamics. Retrieved from http://www.ssc.upenn.edu/ fdiebold/

Dornbush, R. (1998). Capital controls: An idea whose time is gone. In P. Kene (Ed.), Symposium on capital controls. Princeton: Princeton Essays in International Finance, Princeton University Press.

Engle, R. F. (1982). Autoregressive conditional heteroskedasticity with estimates of the variance of United Kingdom inflation. Econometrica, 50, 987-1007.

Fernandes, M., \& Monteiro, M. B. (1997). A procedure for analyzing the persistence in volatility (Um Procedimento para Análise de Persistência na Volatilidade). Revista de Econometria, 17(1), 15-43.

Fraga, A., Goldfajn, I., \& Minella, A. (2003). Inflation targeting in emerging market economies. Brasil: Banco Central do Brasil. Working Paper No. 76.

Gray, S. F. (1996). Modeling the conditional distribution of interest rates as a regime-switching process. Journal of Financial Economics, 42, 27-62.

Haas, M., Mittnik, S., \& Paolella, M. (2004). A new approach to markov-switiching GARCH models. Journal of Financial Econometrics, 2(4), 493-530.

Hamilton, J. D. (1989). A new approach to the economic analysis of nonstationary time series and the business cycle. Econometrica, 57, 357-384.

Hamilton, J. D. (1990). Analysis of time series subject to changes in regime. Journal of Econometrics, 45, 39-70.

Hamilton, J. D. (1991). A quasi-bayesian approach to estimating parameters for mixtures of normal distributions. Journal of Business and Economic Statistics, 9(1), 27-39.

Hamilton, J. D., \& Susmel, R. (1994). Autoregressive conditional heteroscedasticity and changes in regime. Journal of Econometrics, 64, 307-333.

IMF. (2004). Standards and codes: Can they prevent financial crises?. Washington, D.C.: IMF Book Forum.

IMF. (2005). Guidelines for foreign exchange reserve management. Washington, D.C.: IMF.

Inclán, C., \& Tiao, G. C. (1994). Use of cumulative sums of squares for retrospective detection of changes of variance. Journal of the American Statistical Association, 89, 913-923.

Jorion, P. (1998). Value at risk: The new source reference for market risk control (Value at Risk: A Nova Fonte de Referência para o Controle do Risco de Mercado). São Paulo, Brasil: BM\&F.

JP Morgan. (1996). Risk Metrics ${ }^{T M}$. New York, N.Y.: JP Morgan Technical Document. 
Krugman, P. (1997). Currency crisis. Retrieved from http://www.mit.edu/ krugman/

Lamoureux, C. G., \& Lastrapes, W. D. (1990). Persistence in variance, structural change and the GARCH model. Journal of Business and Economic Statistics, 68, 225-234.

Leal, R. (1998). Sudden changes in conditional variance and its consequences for options premium (Mudanças Repentinas na Variância Condicional e Suas Conseqüências Para o Prêmio de Opções). Foz do Iguaçu, Brasil: In Reunião Anual da ANPAD XXII (p. 11).

Leite, H. P., \& Sanvicente, A. Z. (1994). Bovespa index: A standard for Brazilian investments (Índice BOVESPA: Um padrão para os Investimentos Brasileiros). São Paulo, Brasil: Atlas.

Mandelbrot, B. (1963). New methods in statistical economics. Journal of Political Economy, 71(5), 421-440.

Meirelles, H. (2004). Statement by the president of the central bank of Brazil, in the feast commemorating the 18th anniversary of the commodities and futures exchanges (Pronunciamento do Presidente do Banco Central do Brasil, na festa em comemoração aos 18 anos de existência da Bolsa de Mercadorias e Futuros). Retrieved from http://www.bmf.com.br

Mendes, B. (2004). Introduction to extreme events analysis (Introdução à Análise de Eventos Extremos). Rio de Janeiro, Brasil: E-papers Serviços Editoriais Ltda.

Monteiro, J. D., \& Silva, P. M. (2003). Additional risk of loss, extreme value theory and risk management: Application to Portuguese financial markets (Risco de Perda Adicional, Teoria dos Valores Extremos e Gestão do Risco: Aplicação ao Mercado Financeiro Portugues). Retrieved from http://www.yahoo.com.br

Morales, A., \& Schumacher, L. (2003). Market volatility as a soundness indicator: An application to Israel. Washington, IMF. Working Paper 03/47.

Rabi Jr., L. (1996). Identifying trend reversals: An application of Hamiltonian switching regimes models (Identificação de reversões de Tendência: Uma Aplicação do Modelo Hamiltoniano de Switching Regimes). Resenha BM\&F, 110, 33-38.

Razin, A., \& Sadka, E. (2004). A Brazilian-type debt crisis: Simple analytics. Washington, D.C.: IMF Staff Papers.

Schachter, B. (1997). All about value-at-risk ${ }^{\mathrm{TM}}$. An irreverent guide to value at risk. Retrieved from http://www.gloriamundi.org/var/wps.html

Shumway, R. H., \& Stoffer, D. S. (2000). Time series analysis and its applications. New York, N.Y.: Springer-Verlag.

Valls, P., \& Almeida, N. (2000). SWGARCH models applied to the Bovespa Index (Os Modelos SWGARCH aplicados ao IBOVESPA). São Paulo, Brasil: Finance Lab Working Paper, IBMEC.

Vieira Neto, C. A., \& Urban, F. (2001). A model for stress testing least subjective and most comprehensive (Um Modelo de Teste de Stress menos Subjetivo e Mais Abrangente). Retrieved from http://www.risktech.com.br/PDFs/Artigo_Stress.pdf

Zangari, P. (1997). Catering for an event. London, England: Risk. 


\section{Appendix A}
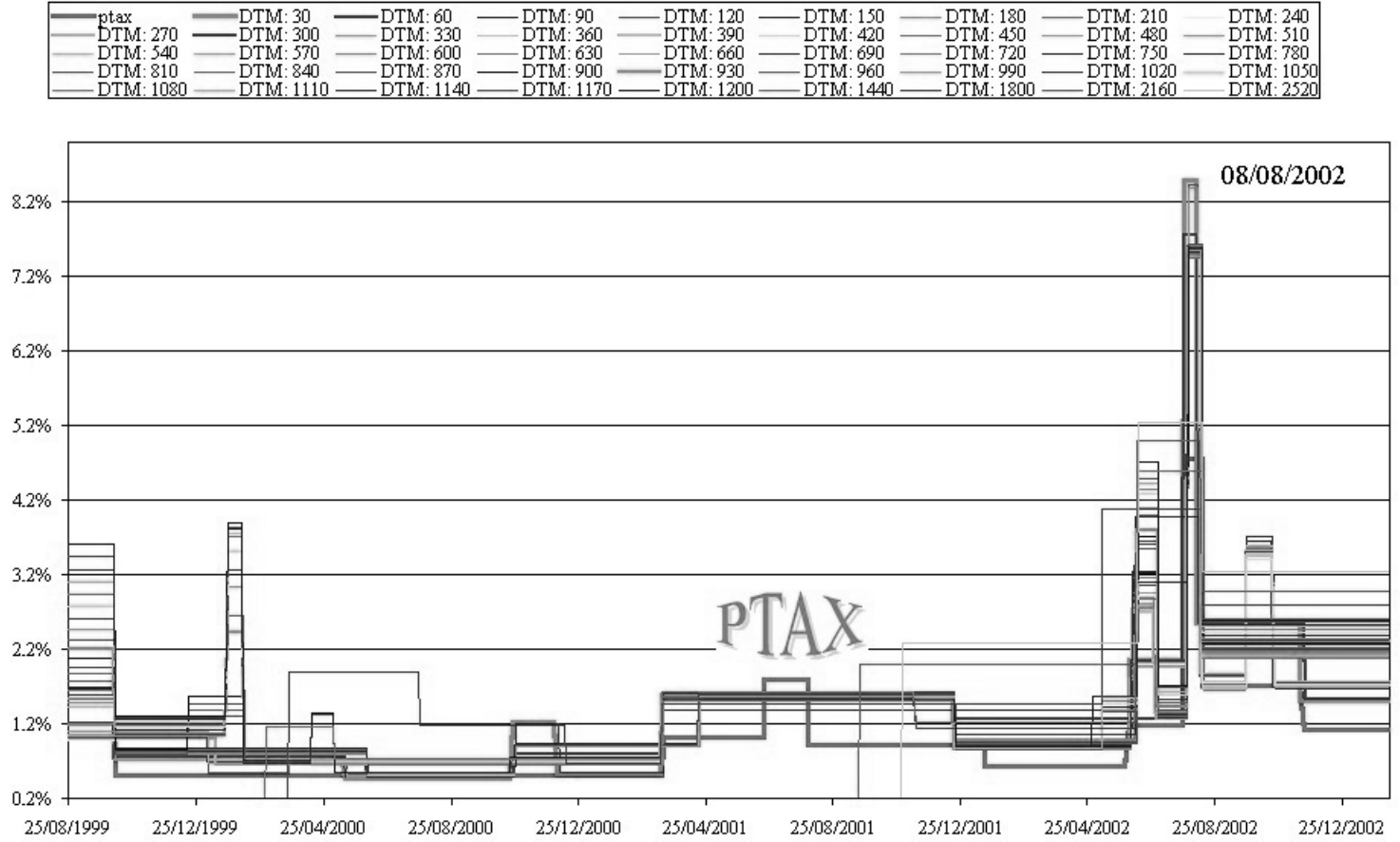
Figure A1. Unconditional volatility: the currency exchange swaps prices series and PTAX. Notes. (1) Period: from 08/25/1999 to 02/07/2003; (2) DTM: days to maturity. PTAX: Spot R\$/US\$ exchange rate; (3) Peak unconditional volatility near 8\%, in August 8, 2002, for all currency exchange swaps. Peak Volatility for PTAX: 4.755\% (from July 26 to August 13, 2002). 